\title{
Some aspects regarding the static behavior of basalt in the machine building industry
}

\author{
Ilie Octavian Popp ${ }^{1, *}$ \\ ${ }^{1}$ Lucian Blaga University of Sibiu, Department of Industrial Machines and Equipment, 550025 \\ Victoriei 10, Sibiu, Romania
}

\begin{abstract}
Basalt is a material available in big quantities in nature. It has a low price and can be used in various domains. It can be relatively easily extracted from natural deposits and processed by means of melting. Melted and recrystallized basalt has demonstrated promising behavior with regards of its use in manufacturing, as reported in the literature. This work aims to present some aspects regarding the opportunity of using basalt in manufacturing the subassemblies of machine-tools. The research was made using grey cast iron and steel parts as reference for a comparative study. The researches presented in this work were focused on analyzing the behavior of basalt parts submitted to static stress. Testing methodology, specific measuring apparatus used, experimental test data records, data processing and resulting conclusions are presented in the paper.
\end{abstract}

\section{Introduction}

During its working regime, a machine-tool is subject to various loads which confer the predominant form of stress. The most important loading factors are:

- the weight of supporting and mobile assembly, of workpiece rigs acting as a static working load;

- the cutting forces, the running mobile assemblies, acting as a dynamic working load;

- frictional loss, the heat recessed while chipping cutting determine thermal deformation.

Structural elements of the machine-tool are subject to stresses in different ways due to all previously presented factors, consequently a lot of research work regarding the use of different materials for manufacturing machine-tools elements is reported in the literature [14]. There are quite few studies reporting basalt as building material for machine-tools elements. However, a literature survey [5-9] shows a tendency to use mineral casting instead of iron casting, due to their superior characteristics. A composition containing basalt, spodumenne and fly ash was found to have the highest flexural strength and lowest thermal expansion coefficient $[1,7]$.

The main purpose of the presented research was to demonstrate that when taking into consideration machine-tools beds and other structural parts, basalt can be accepted as building material. To achieve this goal, the stress behavior for basalt parts must be assessed. Consequently, one of the main contributions of this work is considered proposing basalt as

\footnotetext{
*Corresponding author: ilie.popp@ulbsibiu.ro
} 
solution for structural parts in the machine building industry and to develop an experimental set of test for evaluating its static behavior.

Nowadays there is a technological limit of $800 \mathrm{~mm}$ as main dimension limit for basalt parts. Consequently, a complex machine structure from basalt (like housing, body, trunk, lug support, base) must be built using many basic parts (rungs (draw bar), plates) joined together.

\section{Tests and simulations}

\subsection{General remarks}

In order to assess the stability range of the components within the structures, static stiffness is often used as a characteristic input. For a given part, made from different materials, static stiffness represents the capacity to impede the external forces which tends to deform it. The static stiffness can be defined as the ratio between the force size which acts in assigned direction and the traveling size of respective structure [10].

It comes from stiffness definition the general approach mode used in test methods: taking measurement of displacement generated in closing point by a force well defined in size, direction and sense.

The analysis of the basalts behavior was performed on a representative structural element. Based upon structural machines analysis and technological limits of machining basalt parts, it was selected a natural embedded rectangle plate having dimensions: $250 \mathrm{x}$ $250 \times 40 \mathrm{~mm}$. the shape and dimensions were considered by the author as very common for the structural elements encountered within machine building industry. The laboratory equipment used for unfolding the experimental tests includes: six channels Hottinger bridge, Hottinger force cell, signal convertor and Hewlett Packard graphic plotter (Fig. 1).

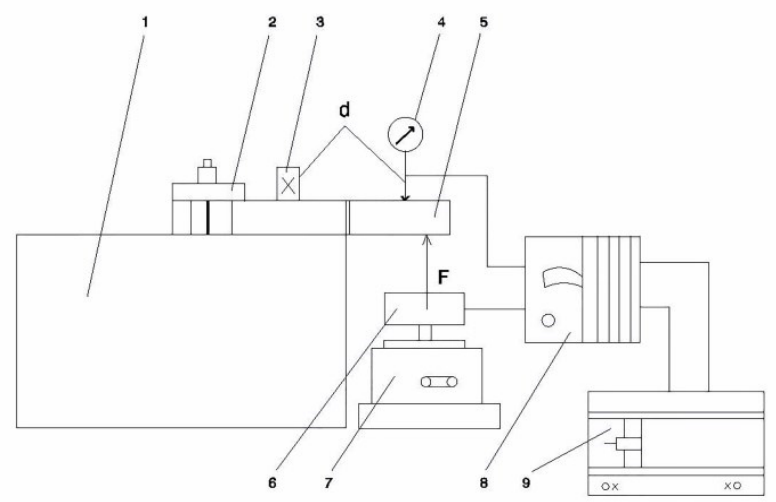

1. Support

2. Structure fasteners (bracket)

3. Magnetic support fixed to the structure

4. Inductive displacement transducer

5. Basalt structure

6. Power transducer (Hottinger)

7. Static loading device

8. 6-channel amplifier bridge (Hottinger)

9. Graphic x-y plotter (HawlettPackard)

Fig. 1. Sketch of the test stand

\subsection{Experimental tests}

The design on the test sample is presented in figure 2. The schematic representation from figure 2 depicts the loading forces positioned on the part, with their directions and application points, situated on the upper face of the part. 
In order to load the test sample, two forces of $250 \mathrm{daN}$ were applied consecutively as presented in figure 2. The application points were situated as follows: F1 eccentric at 40 $\mathrm{mm}$ from the edge of the part and F2 centric at $125 \mathrm{~mm}$ from the table's edge).

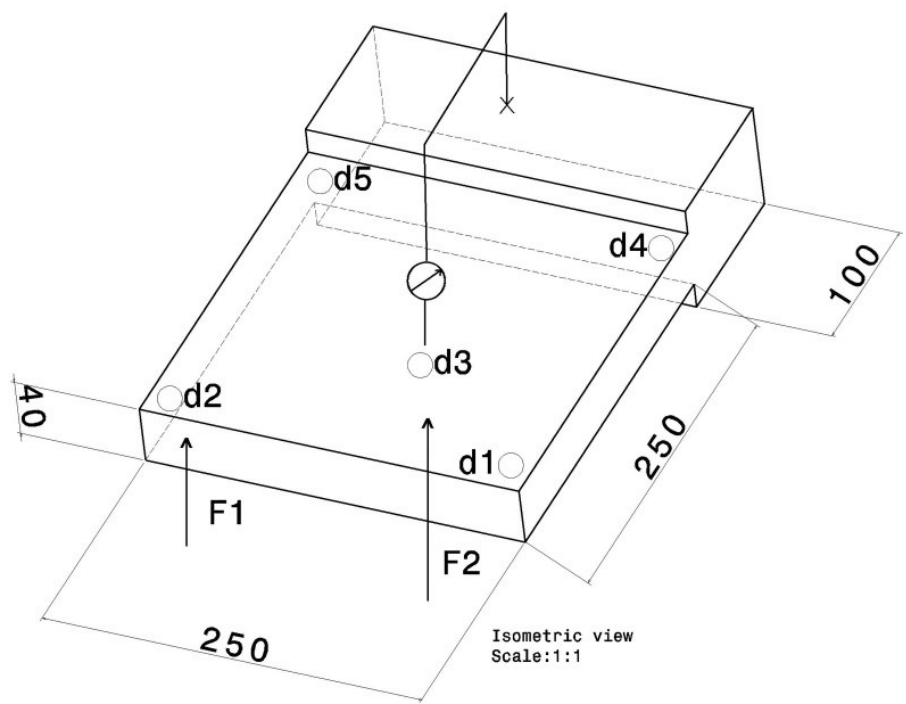

Fig. 2. Test sample (naturally recessed plate type element).

The deformations were measured in all the five point from figure 2, situated symmetrical on the upper face of the test sample. Specific methodology was used to determine the the indicators of directly static stiffness.

The synthetic results of performed tests are presented in table 1 which enclose the values of static elasticity of flexure recorded in all measuring points.

Table 1. Synthetic list of static flexure elasticity values measured

\begin{tabular}{|c|c|c|}
\hline Measurement point & Static elasticity $(\boldsymbol{\mu m} / \mathbf{d a N})$ \\
\hline & $\mathbf{F 1}$ & $\mathbf{F 2}$ \\
\hline $\mathrm{d} 1$ & 0.1917 & 0.1215 \\
\hline $\mathrm{d} 2$ & 0.3186 & 0.1161 \\
\hline $\mathrm{d} 3$ & 0.1242 & 0.0675 \\
\hline $\mathrm{d} 4$ & 0.0216 & 0.0108 \\
\hline $\mathrm{d} 5$ & 0.0108 & 0.0108 \\
\hline
\end{tabular}

\subsection{FEM analysis}

After running the experiments, the Finite Element Method (FEM) was used as theoretical mean for simulation, in order to perform a comparison between experimental and simulated results. The complete set of equations which generally describes the structure behavior has the following form $[10,11]$ :

$$
[\mathrm{M}]\{\ddot{\mathrm{u}}\}+[\mathrm{C}]\{\mathrm{u}\}+[\mathrm{K}]\{\mathrm{u}\}=\{\mathrm{R}\}
$$

where:

[K] - stiffness matrix;

[M] - mass matrix; it contains the terms which defines the net weight of component parts or other implicated mass in dynamic behavior of structure; 
[C] - damping coefficient matrix;

u\} - branch point displacement vector;

$\{\mathrm{u}\}$ - branch point speed vector;

$\{\ddot{\mathrm{u}}\}$ - branch point acceleration vector;

$\{R\}$ - external loading vector.

Particularly on static analysis the speed and acceleration vector are nulled and the terms of loading vector are constant. Static behavior analysis is applied to evaluate the values of structure deformations and stresses. The analysis was by means MARC, a finite element analysis software package. The results obtained running this software include complete information about dimensional variation and about normal and tangential stress distribution.

The initial conditions were the following:

- sample plate dimensions 250 × 250 × $40 \mathrm{~mm}$;

- material: basalt with elasticity modules $\mathrm{E}=85230 \mathrm{MPa}$, contraction coefficient $\Lambda=0.33$;

- load $\mathrm{F}=2500 \mathrm{~N}$ applied in the two points indicated in figure 1 .

The static elasticity modules value was experimentally measured using the electrical strain gauge method. Due to the geometrical symmetry and of the loading and supporting mode the analyzed structure was transformed in a finite element mesh containing hexahedral tridimensional solid elements resulting 1131 mesh point having 3393 degrees of freedom.

The results of FEM analysis for both tests are presented in figures 3 and 4, where in the left side of the figures are presented the displacements $u_{y}[\mathrm{~mm}]$ and on the right side the stresses $\Phi_{11}[\mathrm{MPa}]$.

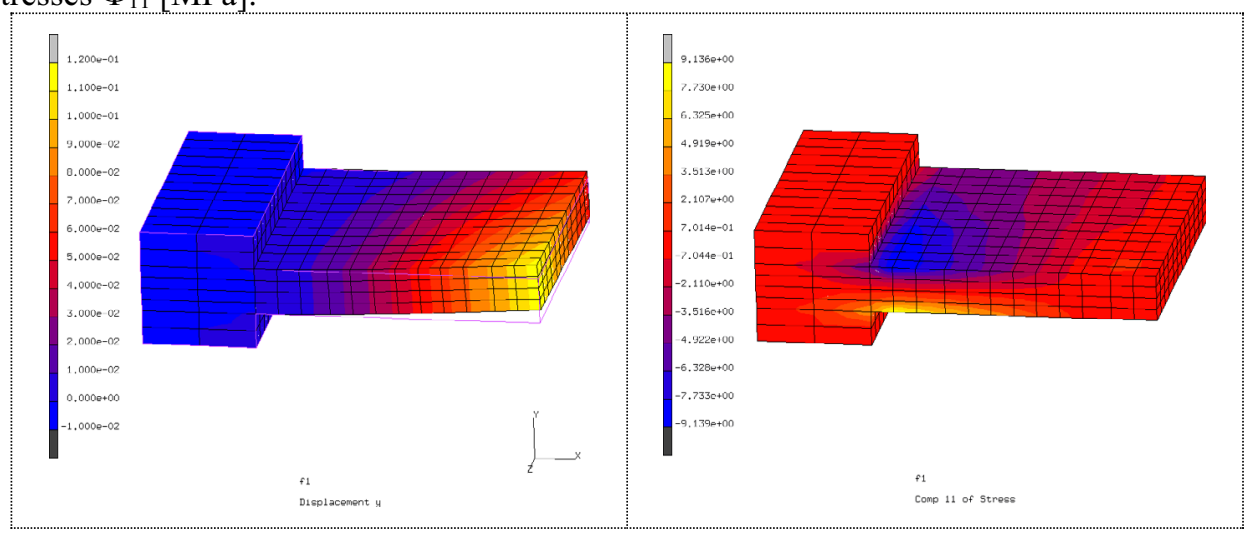

Fig. 3. Displacements $u_{y}[\mathrm{~mm}]$ and o stresses $\Phi_{11}$ for $F_{1}[\mathrm{MPa}]$.

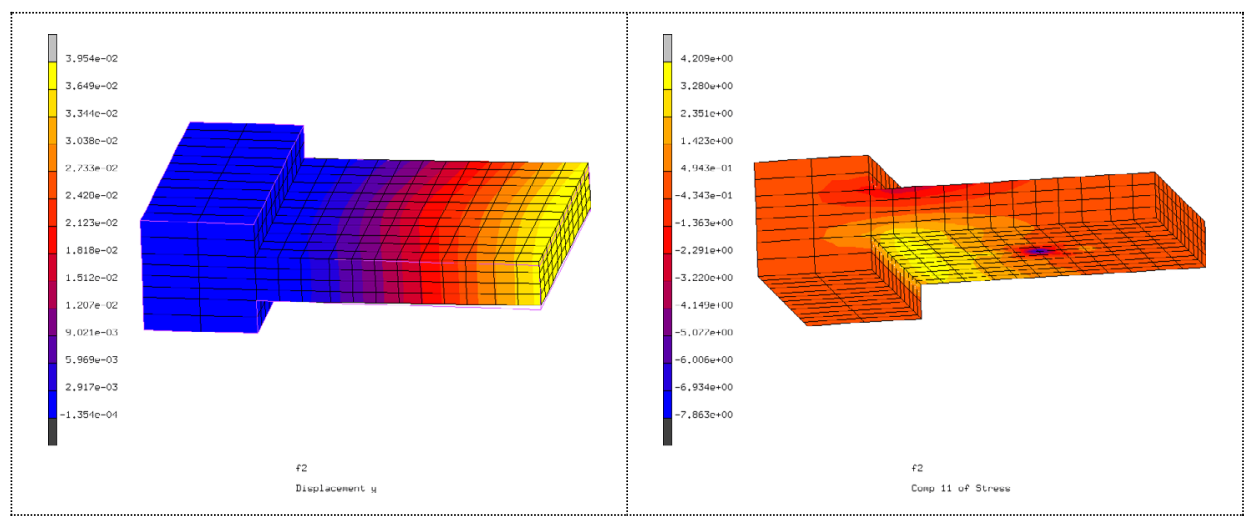

Fig. 4. Displacements $u_{y}[\mathrm{~mm}]$ and o stresses $\Phi_{11}$ for $F_{2}[\mathrm{MPa}]$. 
The analytical solution for the main stress component on $\mathrm{OX}$ direction in $\mathrm{F}_{2}$ loading case is:

$$
\sigma_{11}=\frac{M}{W}=\frac{F l}{\frac{b h^{2}}{6}}=\frac{125 \times 2500}{250 \times 40^{2}} 6=4.687 M P a
$$

The maximum value of $\Phi_{11}$ determined by FEM is $4.209 \mathrm{MPa}$. The difference may be caused by the stress located phenomena in restraining zone where the geometrical structure is different from ideal structure. The displacement values are influenced by elastic modules E and structural geometry.

The analytical solution of $d_{3}$ point displacement equation is:

$$
d_{3}=u_{y(3)}=\frac{1}{3} \frac{F l^{3}}{E I_{z}}=\frac{1}{3} \frac{2500 \times 125^{3}}{85230 \times \frac{250 \cdot 40^{3}}{12}}=0.014322 \mathrm{~mm}
$$

The FEM determined solution is $\mathrm{u}_{\mathrm{y}}=17,977: \mathrm{m}$.

A comparison between measured displacements in each point, obtained by running the FEM analysis and by means of experiments is presented in table 2 .

Table 1. FEM determined and measured displacements

\begin{tabular}{|c|c|c|c|c|}
\hline \multirow{2}{*}{$\begin{array}{c}\text { Measuring } \\
\text { point }\end{array}$} & \multicolumn{3}{|c|}{ DEM isplacement $\mathrm{u}_{\mathrm{y}}[: \mathrm{m}]$} \\
\cline { 2 - 5 } & \multicolumn{3}{|c|}{ experimental } \\
\cline { 2 - 5 } & $\mathrm{F} 1$ & $\mathrm{~F} 2$ & $\mathrm{~F} 1$ & $\mathrm{~F} 2$ \\
\hline $\mathrm{d}_{1}$ & 50.780 & 31.143 & 47.925 & 30.375 \\
$\mathrm{~d}_{2}$ & 85.516 & 31.143 & 79.651 & 29.025 \\
$\mathrm{~d}_{3}$ & 31.142 & 17.977 & 31.051 & 16.875 \\
$\mathrm{~d}_{4}$ & 6.95 & 2.925 & 5.413 & 2.715 \\
$\mathrm{~d}_{5}$ & 3.015 & 2.925 & 2.712 & 2.715 \\
\hline
\end{tabular}

\section{Conclusion}

Through the bibliographic study we have ascertained that the problem of the behavior of the basalt to the specific stress for its use in the manufacturing of the structural elements of the machine tools is not yet addressed.

This fact has led me to research on the use of basalt in the basic structure of machine tools, in the manufacture of structural parts as frames, pillars, housings, supports, etc.

In this paper is presented a part of the study of the static behavior of the basalt subjected to specific machine tool requirements, both experimentally on a basalt plate structure and an analytical model, for comparing the results.

The results of the experiments are quite similar with the results obtained by means of theoretical analysis and FEM simulations. The deformation amplitudes have shown maximum values in the near vicinity and direction of the lading forces application points. Static stiffness has a linear variation on restraint plate structures. When the sample part is subject to eccentric loading forces, the increase in the deformation values is significant (with a size factor of 2.5). If the sample is subject to centric loading forces, symmetrical deformation occurs. 
Finally, comparing the test results with the one obtained for different materials, basalt demonstrated better behavior than steel or grey iron cast parts, which make it suitable for machine-building industry.

\section{References}

1. H.-C. Möhring, C. Brecher, E. Abele, J. Fleischer, F. Bleicher, Materials in machine tool structures, CIRP Annals - Manufacturing Technology, 64 (2), 725-748 (2015)

2. V. Ducatti, R. Lintz, J. Santos, Int. RILEM Conf. on the Use of Recycled Mat. in Building and Structures 925-934 (2004)

3. G.P. Zhang, Y.M. Huang, W.H. Shi, W.P. Fu, Int. J. of Machine Tools \& Man., 699-706 (2003)

4. C. Gornic, Bazaltul materie prima pentru piesele destinate masinilor unelte (Basalt raw material for machine tool parts) ( ICSITMU - Titan, Bucuresti, 1989)

5. N. Kepczak, W. Pawlowski, M\&ME., 17(4), 285-289 (2013)

6. C. Bruni, A. Forcellese, F. Gabrielli and M. Simoncini, J. of Mat. Proc. Tech., 493-499 (2007)

7. H. Haddad, M. Al Kobaisi, Composites B, 3061-3068 (2012)

8. F. Cortes, G. Castillo, Mat. and Design 28, 1461-1466 (2006)

9. T. Erbe, J. Król, R. Theska, Annual Meeting of the American Soc. for Precision Eng. and Twelfth ICPE, 23 (2008)

10. C. Minciu, s.a. Comportarea statica a masinilor unelte (Static behavior of machine tools), (T.C.M.M. 11, Editura Tehnica, Bucuresti, 1995)

11. V. Nastasescu, Metoda elementelor finite - Finite element method, (Editura Academiei Tehnicii Militare, Bucuresti, 1995) 